\title{
Metabolic engineering of Escherichia coli for efficient biosynthesis of fluorescent phycobiliprotein
}

Huaxin Chen ${ }^{1,2,3^{*}}$ and Peng Jiang ${ }^{1,2,3}$

\begin{abstract}
Background: Phycobiliproteins (PBPs) are light-harvesting protein found in cyanobacteria, red algae and the cryptomonads. They have been widely used as fluorescent labels in cytometry and immunofluorescence analysis. A number of PBPs has been produced in metabolically engineered Escherichia coli. However, the recombinant PBPs are incompletely chromophorylated, and the underlying mechanisms are not clear.

Results and discussion: In this work, a pathway for SLA-PEB [a fusion protein of streptavidin and allophycocyanin that covalently binds phycoerythrobilin (PEB)] biosynthesis in E. coli was constructed using a single-expression plasmid strategy. Compared with a previous E. coli strain transformed with dual plasmids, the E. coli strain transformed with a single plasmid showed increased plasmid stability and produced SLA-PEB with a higher chromophorylation ratio. To achieve full chromophorylation of SLA-PEB, directed evolution was employed to improve the catalytic performance of lyase CpcS. In addition, the catalytic abilities of heme oxygenases from different cyanobacteria were investigated based on biliverdin IXa and PEB accumulation. Upregulation of the heme biosynthetic pathway genes was also carried out to increase heme availability and PEB biosynthesis in E. coli. Fed-batch fermentation was conducted for the strain V5ALD, which produced recombinant SLA-PEB with a chromophorylation ratio of $96.7 \%$.
\end{abstract}

Conclusion: In addition to reporting the highest chromophorylation ratio of recombinant PBPs to date, this work demonstrated strategies for improving the chromophorylation of recombinant protein, especially biliprotein with heme, or its derivatives as a prosthetic group.

Keywords: Phycobiliprotein, Phycobilin, Chromophorylation ratio, Plasmid stability, E. coli

\section{Background}

The phycobiliproteins (PBPs) are a family of light-harvesting proteins found in cyanobacteria, red algae and the cryptomonads [1]. Based on their spectrum properties, PBPs are classified into three main types: phycoerythrin (PE), phycocyanin (PC), and allophycocyanin (APC). These proteins absorb strongly in the visible region of the spectrum because they carry various covalently attached linear tetrapyrrole prosthetic groups (phycobilins). Due to their excellent fluorescent properties and their ability to be covalently linked to various biomolecules,

\footnotetext{
*Correspondence: chhx@qdio.ac.cn

${ }^{1}$ Key Laboratory of Experimental Marine Biology, Institute of Oceanology,

Chinese Academy of Sciences, Qingdao 266071, China

Full list of author information is available at the end of the article
}

PBPs have been widely used as fluorescent labels in flow cytometry and immunofluorescence analysis [2].

PBPs are generally extracted and purified from cyanobacteria and red algae [3]. When used as a fluorescent label, phycobiliprotein is often chemically cross-linked to streptavidin [4]. Streptavidin, a biotin-binding protein, is composed of four molecules of streptavidin monomer with four active sites for biotin binding [5]. The affinity of streptavidin for biotin is extremely high, and the Kd value is up to $10^{-13}$ [6]. The streptavidin-linked phycobiliprotein can bind to biotinylated proteins, DNA or other biochemical reagents and can thus be used to probe biological events.

In recent decades, pathways for the most abundant PBPs in cyanobacteria, APC (ApcA/ApcB) and PC 
(CpcA/CpcB), have been elucidated. Phycocyanobilin (PCB) and phycoerythrobilin (PEB) are the major phycobilins attached to APC and PC. These phycobilins originate from cyclic tetrapyrrole (heme). The oxidative cleavage of heme by heme oxygenase (Ho1) produces biliverdin IX $\alpha(\mathrm{BV})$, the first intermediate common to all phycobilins. BV is subsequently reduced by ferredoxindependent bilin reductases to yield PCB, PEB or other types of phycobilins [7]. The attachment of phycobilins to apo-PBPs is catalyzed by different type of lyases [8]. The $\mathrm{CpcE} / \mathrm{F}$ lyase is the first identified enzyme dedicated to phycobilin attachment. This lyase has broad substrate specificity and catalyzes the attachment of PCB to the $\mathrm{PC} \alpha$ subunit. The second identified lyase, $\mathrm{CpcS} / \mathrm{U}$, is responsible for the attachment of PCB to the Cys-82 residues on the APC $\alpha$ and $\beta$ subunits and on the PC $\beta$ subunit. In some cyanobacteria, such as Synechococcus sp. PCC 7002 and Synechocystis sp. PCC 6803, CpcS/U is composed of a heterodimer of two similar proteins, designated $\mathrm{CpcS}-\mathrm{I}$ and $\mathrm{CpcU}[9,10]$, while in other cyanobacteria, such as Nostoc sp. PCC 7120, the CpcS lyase exists in a monomeric, single subunit form [11]. The third identified CpcT lyase is a homodimer and catalyzes the attachment of PCB to the Cys-153 residue in the PC $\beta$ subunit [12]. With the development of metabolic engineering techniques, biosynthetic pathways for PBPs have been constructed, and a number of holo-PBPs had been successfully produced in Escherichia coli [13-16]. These recombinant PBPs could easily be purified using immobilized metal affinity chromatography, and they retained the spectroscopic properties of native phycobiliprotein. In our recent work, the biosynthetic pathway for production of SLA-PEB (a fusion protein of streptavidin and allophycocyanin that covalently binds PEB) was constructed in E. coli. The fusion protein with PEB as chromophore was successfully produced in E. coli. While retaining the fluorescent properties, the fusion protein could bind biotinynated antibody and could be used as fluorescent label in immunofluorescence assay [17].

The recombinant PBPs produced in E. coli, however, were partially chromophorylated. The chromophorylation ratio of PBPs (the percentage of chromophorylated PBP to total recombinant PBP) was reported to range from 17.4 to $71.9 \%[14,17,18]$, indicating that a faction of the recombinant PBP was produced as its apo-form in E. coli. The apo-PBPs are difficult to remove from the PBP mixture during protein purification and lead to low detection sensitivity in immunofluorescence assays due to the lack of fluorescence emission. It was speculated that the incomplete chromophorylation is due to unfavorable codon usage that limits the expression of large amounts of lyases and phycobilins by E. coli, or it is due to aggregation of the recombinant proteins into insoluble inclusion bodies [13]. In addition, since heme serves as the precursor for phycobilin biosynthesis, depletion of heme could be a potential limiting factor for the chromophorylation of recombinant PBPs. In a recent work, an in vitro chromophore attachment reaction system was established in an attempt to improve the chromophorylation of recombinant PBP [19]. Spectral analysis showed that phycobilin attached rapidly to the recombinant PBP during the reaction. The chromophorylation ratio was elevated from 21.1 to $86.5 \%$. Immunofluorescence assays showed that recombinant PBP with a higher chromophorylation ratio had a higher detection signal. However, the in vitro chromophore attachment reaction is time- and labor-consuming due to the need to purify phycobilin, lyases and recombinant PBPs.

In this study, we tried to elucidate the mechanisms underlying the incomplete chromophorylation of recombinant SLA-PEB and construct an efficient pathway for SLA-PEB production in E. coli. It was found that the $E$. coli strain transformed with dual expression plasmids lost one or both plasmids during the course of fermentation. To improve plasmid stability, we reconstructed the biosynthetic pathway in $E$. coli by using one expression vector. This strain, which has increased plasmid stability, retained the entire SLA-PEB biosynthetic pathway and produced recombinant SLA-PEB with a higher chromophorylation ratio. To achieve full chromophorylation, the catalytic abilities of Hol from different cyanobacteria were investigated based on BV and PEB accumulation. Upregulation of the heme biosynthetic pathway genes was also carried out to increase heme availability and PEB biosynthesis in E. coli. These strategies enable the efficient production of SLA-PEB in E. coli. In a $5 \mathrm{~L}$ fermentor, the engineered strain V5ALD produced $56.4 \mathrm{mg} / \mathrm{L}$ SLA-PEB with a chromophorylation ratio of $96.7 \%$.

\section{Materials and methods Construction of plasmids and strains}

An E. coli strain for SLA-PEB biosynthesis was constructed in our previous work [17]. This engineered strain (denoted hereafter as SLA-V1) contained two expression plasmids: pCDF-SLA-cpcS and pRSF-PHo1$p e b S$. The fusion protein SLA-PEB with $6 \times$ His tag at its $\mathrm{N}$-terminal can be easily purified by $\mathrm{Ni}^{2+}$ chelating affinity chromatography. To express the SLA-PEB pathway genes from one expression vector, $\mathrm{PHo1}$ and $\mathrm{pebS}$ (coding phycoerythrobilin synthase) were designed as a polycistron. This polycistron was chemically synthesized and ligated into the second expression cassette of the vector pRSFDuet-1, generating the plasmid pRSF-PHo1-pebS. The BamHI/SacI fragment of SLA from pCDF-SLA-cpcS was ligated into similarly digested pRSF-PHo1-pebS, 
generating the plasmid pRSF-SLA-PHo1-pebS. $c p c S$ was amplified by PCR using primers $\mathrm{cPcSF}$ and $\mathrm{cpcSR}$ with a ribosomal binding site engineered on the primer cpcSF. The PCR product was digested with SacI/SalI, purified and ligated into similarly digested pRSF-SLA-PHo1$p e b S$, generating the expression plasmid pRSF-SLA-cpcSPHo1-pebS (Fig. 1). This plasmid was then transformed into competent $E$. coli BL21(DE3), generating the strain SLA-V2 (Fig. 2).

Ho1 genes from Synechococcus sp. PCC 7002(7Ho1), Synechococcus elongatus BP-1(BHo1), Synechococcus sp. PCC 9311(9Ho1), Synechocystis sp. PCC 6803(6Ho1) and cyanophage PSSM-2(PHo1) were optimized according to $E$. coli codon usage and artificially synthesized. These Hol genes were digested with NdeI/BglII and cloned into similarly digested pRSFDuet-1, generating the plasmids pRSF-7Ho1, pRSF-BHo1, pRSF-9Ho1, pRSF$6 \mathrm{Ho} 1$ and pRSF-PHo1. These plasmids were individually transformed into E. coli BL21(DE3), generating the BVproducing strains EBV7, EBVB, EBV9, EBV6 and EBVP. The pebS gene was amplified using the primers pebSF and pebSR, digested with $B g l \mathrm{II} / K p n \mathrm{I}$ and ligated into similarly digested pRSF-7Ho1, pRSF-BHo1, pRSF-9Ho1, pRSF-6Ho1 and pRSF-PHo1, generating the plasmids pRSF-7Ho1-pebS, pRSF-BHo1-pebS, pRSF-9Ho1-pebS, pRSF-6Ho1-pebS and pRSF-PHo1-pebS, respectively. These plasmids were individually transformed into competent $E$. coli $\mathrm{BL} 21(\mathrm{DE} 3)$, generating the $\mathrm{PEB}$-producing strains PEB7, PEBB, PEB9, PEB6 and PEBP.

The NdeI/BglII fragments of $H o 1$ were ligated into NdeI/BglII digested pRSF-SLA-cpcSM7-PHo1-pebS, generating the plasmid pRSF-SLA-cpcSM7-BHo1-pebS, pRSF-SLA-cpcSM7-6Ho1-pebS, pRSF-SLA-cpcSM77Ho1-pebS, pRSF-SLA-cpcSM7-9Ho1-pebS, respectively. These plasmids were individually transformed into $E$. coli BL21(DE3), generating the strains SLA-V4B, SLA-V46, SLA-V47, SLA-V49, respectively.

hemL (from E. coli) and hemA (a mutant of hemA from Salmonella arizona, [20]) were designed as a polycistron with a ribosomal binding site engineered upstream of hemA. This polycistron was chemically synthesized and ligated into the first expression cassette of the plasmid pCDFDuet-1, generating pCDF-hemLA. The expression cassette including $\mathrm{T} 7$ promoter, hemLA and terminator was then amplified from pCDF-hemLA with the primers hemLAF and hemLAR (Additional file 1: Table S1). The PCR product was digested with $S a c I / E c o R I$, purified and ligated into the similarly digested plasmid pKIKOars$B C \mathrm{~m}$ [21], generating pKIKOarsB-hemLA. hemB was amplified from $E$. coli genomic DNA with the primers hemBF and hemBR (Additional file 1: Table S1). The PCR product was digested with $N d e \mathrm{I} / \mathrm{XhoI}$ and ligated into similarly digested pKIKOarsB-hemLA, generating plasmid pKIKOarsB-hemLAB. Following a similar procedure, pKIKOarsB-hemLAD, pKIKOarsB-hemLAF, pKIKOarsB-hemLAG, and pKIKOarsB-hemLAH were constructed. These plasmids were individually electroporated into E. coli BL21(DE3) transformed with plasmid pKD46 [22], generating the E. coli strains EAL, EALB, EALD, EALF, ELAG and EALH. Integration of the expression cassettes was confirmed by PCR using gene-specific primers and chromosome-specific primers (Additional file 1: Table S1). pRSF-SLA-cpcSM7-BHo1pebS was individually transformed into the strains EAL, EALB, EALD, EALF, ELAG and EALH, generating the E. coli strains SLA-V5AL, SLA-V5ALB, SLA-V5ALD, SLA-V5ALF, SLA-V5ALG and SLA-V5ALH, respectively (Fig. 2, Table 1).

\section{Directed evolution of CpcS}

The diversify PCR Random Mutagenesis Kit (TaKaRa, Japan) was used to generate a $c p c S$ mutant library. The plasmid pCDF-SLA-cpcS at a concentration of $5 \mathrm{ng} / \mu \mathrm{L}$ was used as the DNA template, and cpcSMF and cpcSMR were used as the primers (Additional file 1: Table S1). The buffer condition was chosen to obtain a mutagenesis rate of 4.6 mutations per $1000 \mathrm{bp}$. The cycling conditions were $94{ }^{\circ} \mathrm{C}$ for $30 \mathrm{~s}, 94{ }^{\circ} \mathrm{C}$ for $30 \mathrm{~s}, 68^{\circ} \mathrm{C}$ for 1 min $(25$ cycles $)$, and $68{ }^{\circ} \mathrm{C}$ for $1 \mathrm{~min}$. The mutagenized cpcS fragment was digested with SacI/SalI, and cloned into similarly digested pRSF-SLA-cpcS-PHo1-pebS. The ligation reaction mixture was then transformed into ultra-competent E. coli $\mathrm{T} 1$ for the generation of a random mutant library.

Escherichia coli BL21(DE3) was transformed with the plasmid library. The transformants were spread on $\mathrm{LB}$ agar plates $(5 \mathrm{~g} / \mathrm{L}$ yeast extract, $10 \mathrm{~g} / \mathrm{L}$ tryptone and $10 \mathrm{~g} / \mathrm{L} \mathrm{NaCl}, 10 \mathrm{~g} / \mathrm{L}$ agar, $\mathrm{pH}$ 7.4). The LB agar plates contained $1.0 \mathrm{mM}$ ALA and $1.0 \mathrm{~g} / \mathrm{L}$ lactose, and were cultivated at $18{ }^{\circ} \mathrm{C}$ for $96-120 \mathrm{~h}$ in darkness. Positive colonies were selected according to color change. The detailed procedure is described in Additional file 1: Figure S1.

\section{Analysis of BV and PEB}

For the analysis of BV and PEB, the method described by Frankenberg was basically followed [23]. The BV and PEB in E. coli cells was extracted with acetone overnight in darkness. The extractions were filtered through 0.45 $\mu \mathrm{m}$ polytetrafluoroethylene syringe filter and then were resolved by reversed-phase chromatography using an Agilent Technologies 1260 system. The HPLC column was a $4.6 \times 250-\mathrm{mm}$ Phenomenex Ultracarb analytical column. The mobile phase consisted of acetone and $20 \mathrm{mM}$ formic acid (50:50 by volume), and the flow rate was $0.6 \mathrm{~mL} / \mathrm{min}$. The eluates were monitored at 650,560 , and $380 \mathrm{~nm}$ using an Agilent Technologies 1260 series diode array detector. As needed, complete spectra were 


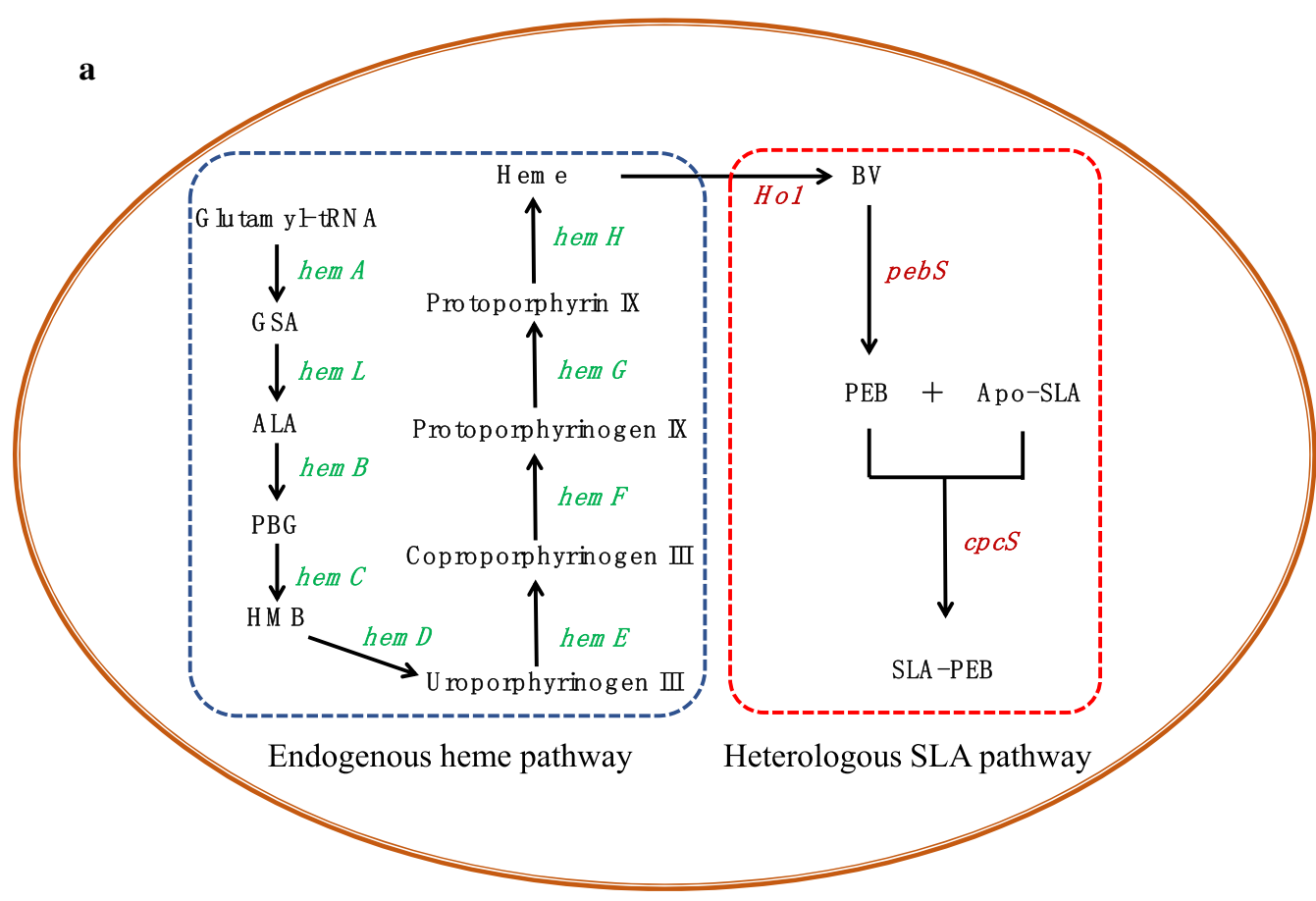

b
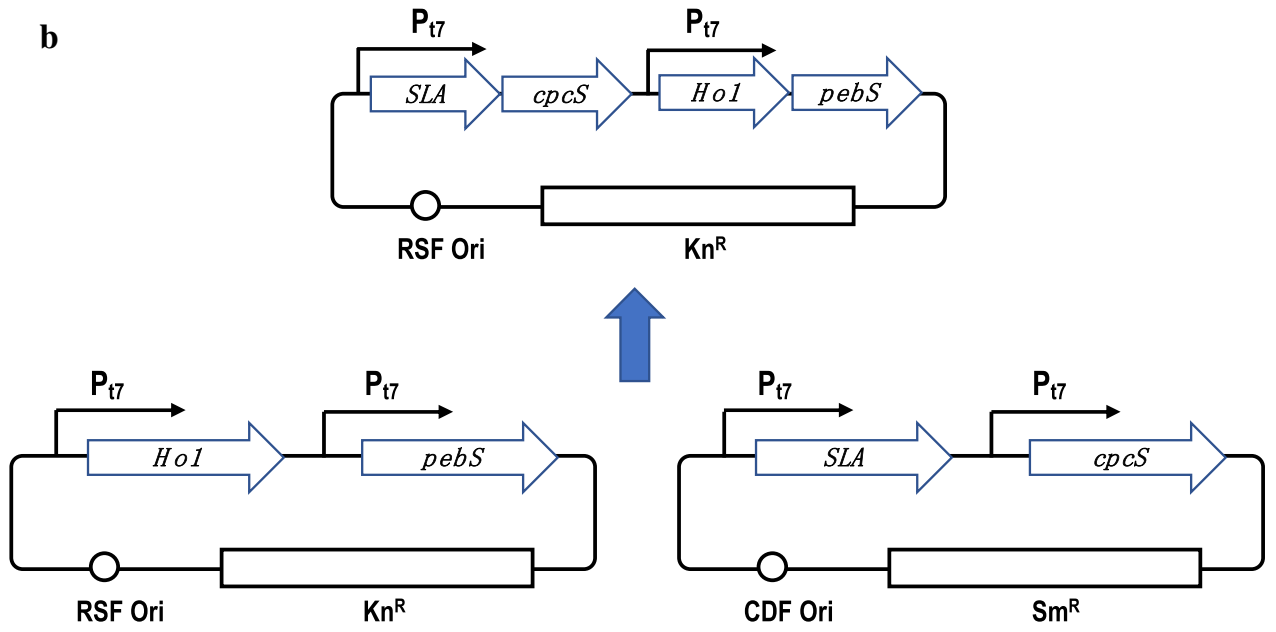

Fig. 1 Schematic presentation of strategy for SLA-PEB biosynthesis in E. coli. a Pathway for SLA-PEB biosynthesis. The pathway for SLA-PEB is divided into two modules: the endogenous heme pathway and the heterologous SLA pathway. GSA glutamate-1-semialdehyde, ALA 5-aminolevulinic acid, PBG porphobilinogen, HMB hydroxymethylbilane, HemA glutamyl-tRNA reductase, HemL glutamate-1-semialdehyde aminotransferase, HemB 5-aminolevulinic acid dehydratase, HemC porphobilinogen deaminase, HemD uroporphyrinogen III synthase, HemE uroporphyrinogen decarboxylase, HemF coproporphyrinogen III oxidase, HemG protoporphyrin oxidase, HemH ferrochelatase, Hol heme oxygenase 1, pebS phycoerythrobilin synthase, CpCS lyase. b Plasmid construction: the four genes required for SLA-PEB biosynthesis were cloned into the plasmids pCDFDuet-1 and pRSFDuet-1 or into a single plasmid pRSFDuet-1

obtained for the peaks desired. Peak areas were quantified using Agilent Technologies Chemstation software.

\section{Media and culture conditions}

LB medium was used for $E$. coli cultivation for the DNA manipulations and seed cultures. For expression of foreign proteins, TB medium was used, which contains $12 \mathrm{~g} / \mathrm{L}$ tryptone, $24 \mathrm{~g} / \mathrm{L}$ yeast extract, $4 \mathrm{~g} / \mathrm{L}$ glycerol, $2.31 \mathrm{~g} / \mathrm{L} \mathrm{KH}_{2} \mathrm{PO}_{4}, 12.54 \mathrm{~g} / \mathrm{L} \mathrm{K}_{2} \mathrm{HPO}_{4}$. Kanamycin $(\mathrm{Km}, 100 \mu \mathrm{g} / \mathrm{mL})$ and/or spectinomycin $(\mathrm{Sm}, 100 \mu \mathrm{g} / \mathrm{mL})$ were added to culture medium to provide selective pressure. Single colonies of recombinant $E$. coli were grown 
Table 1 Plasmids used in this study

\begin{tabular}{|c|c|c|}
\hline Plasmids & Description & Source \\
\hline pRSFDuet-1 & Double T7 promoters, RSF ori, $\mathrm{Km}^{\mathrm{R}}$ & Novagen \\
\hline pCDFDuet-1 & Double T7 promoters, P15A ori, $\mathrm{Cm}^{\mathrm{R}}$ & Novagen \\
\hline pRSF-PHo1-pebS & pRSFDuet-1 containing PHol and pebS & Wu et al. [17] \\
\hline pCDF-SLA-CPCS & pCDFDuet-1 containing SLA and $c p c S$ & Wu et al. [17] \\
\hline pRSF-SLA-cpcS-PHo1-pebS & pRSFDuet-1 containing SLA and $a p c A, c p c S, P H O 1$ and pebS & This study \\
\hline pRSF-SLA-cPcSM7-BHo1-pebS & pRSFDuet-1 containing SLA and $a p c A, c p c S M 7, B H o 1$ and pebS & This study \\
\hline pRSF-SLA-cpcSM7-6Ho1-pebS & pRSFDuet-1 containing SLA and $a p c A, c p c S M 7,6 \mathrm{Ho}^{1}$ and pebS & This study \\
\hline pRSF-SLA-cpcSM7-7Ho1-pebS & pRSFDuet-1 containing SLA, cPCSM7, 7Hol and pebS & This study \\
\hline pRSF-SLA-cPcSM7-9Ho1-pebS & pRSFDuet-1 containing SLA, CPCSM7, $9 \mathrm{Ho} 1$ and pebS & This study \\
\hline pRSF-SLA-cpcSM7-PHo1-pebS & pRSFDuet-1 containing SLA, cpcSM7, PHol and pebS & This study \\
\hline pRSF-PHO1 & pRSFDuet-1 containing PHol & This study \\
\hline pRSF-6Hol & pRSFDuet-1 containing $6 \mathrm{Ho} 1$ & This study \\
\hline pRSF-7Hol & pRSFDuet-1 containing 7Hol & This study \\
\hline pRSF-9Hol & pRSFDuet-1 containing 9Hol & This study \\
\hline pRSF-BHol & pRSFDuet-1 containing $\mathrm{BHO}_{\mathrm{O}} \mathrm{I}$ & This study \\
\hline pRSF-6Ho1-pebS & pRSFDuet-1 containing $6 \mathrm{Ho}_{\mathrm{O}} 1$ and pebs & This study \\
\hline pRSF-7Ho1-pebS & pRSFDuet-1 containing $7 \mathrm{Ho}_{\mathrm{O}} \mathrm{\text {and }}$ pebs & This study \\
\hline pRSF-9Ho1-pebS & pRSFDuet-1 containing $9 \mathrm{Ho}_{\mathrm{O}} \mathrm{l}$ and pebs & This study \\
\hline pRSF-BHol-pebS & pRSFDuet-1 containing BHoland pebS & This study \\
\hline pKD46 & repA101ts and oriR101 ParaB exo, bet, gam araC bla & Datsenko and Wanner [22] \\
\hline pKIKOarsBCm & R6K ori, $\mathrm{Cm}^{\mathrm{R}}$ & Sabri et al. [21] \\
\hline pKIKOarsB-hemLA & pKIKOarsBCm containing expression cassette of hemLA & This study \\
\hline pKIKOarsB-hemLAB & pKIKOars $B C m$ containing expression cassette of hem $L A B$ & This study \\
\hline pKIKOarsB-hemLAD & pKIKOars $B C m$ containing expression cassette of hemLAD & This study \\
\hline pKIKOarsB-hemLAF & pKIKOarsBCm containing expression cassette of hemLAF & This study \\
\hline pKIKOarsB-hemLAG & pKIKOars $B C m$ containing expression cassette of hemLAG & This study \\
\hline pKIKOarsB-hemLAH & pKIKOars $B C m$ containing expression cassette of hemLAH & This study \\
\hline
\end{tabular}

in $3 \mathrm{~mL} \mathrm{LB}$ medium. $15 \mathrm{~mL}$ of overnight seed cultures were then inoculated into $300 \mathrm{~mL}$ of TB medium containing the appropriate antibiotics and cultured at $37^{\circ} \mathrm{C}$ until the optical density at $600 \mathrm{~nm}$ reached 0.8 . The cultures were then cooled to $18{ }^{\circ} \mathrm{C}$, and the expression of the foreign genes was induced by the addition of isopropyl$\beta$-D-thiogalactoside (IPTG) at a final concentration of $0.1 \mathrm{mM}$. After a further incubation for $24 \mathrm{~h}$ at $18{ }^{\circ} \mathrm{C}$ in the dark, the $E$. coli cells were harvested by centrifugation at $6000 \times g$ for $10 \mathrm{~min}$.

The fed-batch fermentation was performed in a $5 \mathrm{~L}$ fermentor (BioF6005S-G, China). 2.0\% inoculation of overnight seed culture was transferred into the fermentor with $2.5 \mathrm{~L} \mathrm{~TB}$ medium. The constant feeding mode $(0.01 \mathrm{~g} / \mathrm{L} / \mathrm{min})$ was employed to achieve high cell density. The feeding medium was composed of $200 \mathrm{~g} / \mathrm{L}$ gluocose, $5 \mathrm{~g} / \mathrm{L} \mathrm{NaCl}, 5 \mathrm{~g} / \mathrm{L} \mathrm{MgSO} 4 \cdot \mathrm{H}_{2} \mathrm{O}, 7 \mathrm{~g} / \mathrm{L} \mathrm{KH}_{2} \mathrm{PO}_{4}, 8 \mathrm{~g} / \mathrm{L}$ $\mathrm{K}_{2} \mathrm{HPO}_{4}$. The culture was cooled to $18^{\circ} \mathrm{C}$ when the cells were in the mid-exponential stage. The cells were then induced with $0.5 \mathrm{mM}$ IPTG and cultivated for $18 \mathrm{~h}$.

\section{Purification of the fusion proteins}

The cells were suspended in $30 \mathrm{~mL}$ of binding buffer (20 mM sodium phosphate, $500 \mathrm{mM}$ sodium chloride and $20 \mathrm{mM}$ imidazole, $\mathrm{pH}$ 7.4) and disrupted by sonication for $30 \mathrm{~min}$ on ice. After centrifugation at $6000 \times g$ for $30 \mathrm{~min}$ at $4{ }^{\circ} \mathrm{C}$, the supernatants were loaded onto a preequilibrated column of Chelating Sepharose (GE Healthcare BioScience, Sweden) charged with $\mathrm{Ni}^{2+}$. The column was then washed with washing buffer $(20 \mathrm{mM}$ sodium phosphate, $500 \mathrm{mM}$ sodium chloride and $50-100 \mathrm{mM}$ imidazole, $\mathrm{pH}$ 7.4) to remove weakly bound proteins. The fusion proteins were eluted with elution buffer $(20 \mathrm{mM}$ sodium phosphate, $500 \mathrm{mM}$ sodium chloride and $500 \mathrm{mM}$ imidazole, $\mathrm{pH}$ 7.4). The high-concentration imidazole was removed using a Sephadex G25 column. The peak fraction was collected and concentrated by ultrafiltration. Protein concentrations were measured by the dye-binding method of Bradford using a commercial kit (BestBio, China). 


\section{SDS-PAGE analysis}

Expression of Ho1 in E. coli was analyzed by SDS-PAGE. E. coli cells expressing Hol were disrupted by sonication and then centrifugated at $6000 \times g$ for $30 \mathrm{~min}$ at $4{ }^{\circ} \mathrm{C}$. The supernatant was mixed with loading buffer and boiled for $10 \mathrm{~min}$. $10 \mu \mathrm{L}$ protein samples were loaded on $12 \%$ acrylamide gel. Resolved proteins were visualized by staining with Coomassie Blue.

\section{Spectral analysis}

Absorption spectra were obtained using a UV-1801 spectrophotometer (Rayleigh, China) with a $0.5 \mathrm{~cm}$ path length cuvette. The wavelength range was from 250 to $700 \mathrm{~nm}$, and the sample interval was set to $1 \mathrm{~nm}$ with a scan speed of $240 \mathrm{~nm} / \mathrm{min}$.

The fluorescence emission spectra were analyzed using an F-4500 fluorescence spectrophotometer (Hitachi, Japan). The excitation wavelength was $520 \mathrm{~nm}$, and the emission spectra were recorded from 540 to $610 \mathrm{~nm}$. The emission and excitation slit widths were set to $5 \mathrm{~nm}$ with a scan speed of $240 \mathrm{~nm} / \mathrm{min}$.

The recombinant proteins were denatured in $8.0 \mathrm{M}$ urea $(\mathrm{pH}$ 1.5). The PEB concentrations were calculated using an excitation coefficient of $42.8 \mathrm{mM}^{-1} \mathrm{~cm}^{-1}$ at $560 \mathrm{~nm}$. To calculate the chromophorylation ratio, the concentration of PEB was divided by the concentration of purified recombinant proteins.

\section{Heme determination}

The intracellular heme concentration was determined according to the procedure described by Sassa with slight modification [24, 25]. The pellets were washed once with water, resuspended in $500 \mu \mathrm{L}$ of $20 \mathrm{mM}$ oxalic acid and then stored in the dark at $4{ }^{\circ} \mathrm{C}$ for $16 \mathrm{~h}$. After the acid extraction, $500 \mu \mathrm{L}$ of $2 \mathrm{M}$ preheated oxalic acid was added. Half of the mixture was transferred to a new amber centrifuge tube and heated to $95{ }^{\circ} \mathrm{C}$ for 30 min, during which the other half mixture was kept at room temperature. Two replicate $200 \mu \mathrm{L}$ aliquots of each sample (heated and unheated) were measured in a microplate reader (Tecan) with excitation at $400 \mathrm{~nm}$ and emission measurement at $620 \mathrm{~nm}$. A standard curve was constructed using different concentrations of hemin (Sigma-Aldrich).

\section{Plasmid stability analysis}

The plasmid stability for the strains SLA-V1 and SLA-V2 were compared at the end of expression period. SLA-V1 was grown in $\mathrm{TB}$ medium containing $100 \mu \mathrm{g} / \mathrm{mL} \mathrm{Sm}$ and $100 \mu \mathrm{g} / \mathrm{mL} \mathrm{Km}$, while SLA-V2 was grown in TB medium containing $100 \mu \mathrm{g} / \mathrm{mL} \mathrm{Km}$. To evaluate the effect of IPTG induction on plasmid stability in these strains, these cultures were induced with or without IPTG at a final concentration of $0.1 \mathrm{mM}$. One hundred microliter samples were taken from flasks at the end of the $24 \mathrm{~h}$ expression period. Each sample was diluted in LB medium and spread on nonselective LB agar plates. These plates were incubated at $37^{\circ} \mathrm{C}$ for $16 \mathrm{~h}$. Individual colonies were randomly chosen and replica-plated on various selective LB plates containing $100 \mu \mathrm{g} / \mathrm{mL} \mathrm{Sm}, 100 \mu \mathrm{g} / \mathrm{mL} \mathrm{Km}$, or $100 \mu \mathrm{g} / \mathrm{mL} \mathrm{Sm}$ and $100 \mu \mathrm{g} / \mathrm{mL} \mathrm{Km}$. The plasmid stability was defined as the fraction of plasmid(s)-bearing cells and was determined by taking the ratio of the number of colonies on the selective plates to the total number of transferred colonies.

To determine plasmid structural stability, colony PCR amplification using primers duetup1/duetup2 and T7 terminator was carried out to analyze the stability of expression cassettes.

\section{Results and discussion}

Increasing the chromophorylation ratio of SLA-PEB by improving plasmid stability

The engineered E. coli strain SLA-V1 was constructed in our previous study to produce SLA-PEB. In this strain, the fusion protein (SLA) of core streptavidin from

Table 2 DNA and amino acid changes in the CpcS mutants and chromophorylation ratios of SLA-PEB purified from the wild type and mutant strains

\begin{tabular}{llllc}
\hline Strains & CpcS mutants & Base changes & Residual changes & $\begin{array}{c}\text { Chromophorylation } \\
\text { ratio (\%) }\end{array}$ \\
\hline SLA-V1 & CpCS & - & - & $16.2 \pm 1.2$ \\
SLA-V2 & CpCS & - & - & $38.6 \pm 4.6$ \\
SLA-V3-2 & CpCSM2 & T100C, A125G & S34P, E42G & $56.2 \pm 6.0$ \\
SLA-V3-7 & CpCSM7 & A302G, A460T & E101G, A177P & $64.7 \pm 3.2$ \\
SLA-V3-9 & CPCSM9 & T30C, A167G, A302G & Q56R, E101G & $46.9 \pm 5.5$ \\
SLA-V3-12 & CPCSM12 & A287G, C316T, T410C & Q96R, I137T & $61.4 \pm 5.8$ \\
SLA-V3-16 & CPCSM16 & T127C, T172C, A221G & Y58H, D74G & $53.6 \pm 2.7$ \\
\hline
\end{tabular}

Data represent mean $\pm S D$ from three independent experiments 
Streptomyces avidinii and allophycocyanin alpha subunit from thermophilic cyanobacterium Thermosynechococcus elongatus $\mathrm{BP}-1$, together with lyase $\mathrm{CpcS}$ from Thermosynechococcus elongatus BP-1 and PEB producing enzymes (PHo1 and PebS) from cyanophage PSSM-2, were co-expressed in E. coli. Two plasmids for were used for the expression of the four genes required for SLA-PEB biosynthesis [17]. The recombinant SLA-PEB, however, was incompletely chromophorylated, with a chromophorylation ratio of $16.2 \%$ (Table 2). This result agreed with previous reports that PBPs were partially chromophorylated when they were expressed in $E$. coli $[13,14$, 18]. The underlying mechanisms are not clear at present. Since incomplete chromophorylation leads to low fluorescence emission and detection sensitivity, it is crucial to achieve full chromophorylation of SLA-PEB. So far, most recombinant phycobiliproteins were expressed in E. coli using dual or multiple plasmid expression systems $[13,14,19]$. The genes responsible for PBP biosynthesis were expressed using two or more plasmids. Theoretically, the pathway works efficiently only if all of the genes are expressed successfully and in the proper balance. However, the expression plasmid(s) might be lost during the expression of foreign proteins, even in the presence of antibiotic [26-28]. We speculate that plasmid stability in E. coli is an important factor affecting the chromophorylation of recombinant SLA-PEB.

The plasmid stability during fermentation was examined for the strain SLA-V1. A fraction of induced E. coli cells could not grow on selective plates, indicating plasmid instability in the E. coli cells. Under uninduced conditions, the E. coli cells had high plasmid stability. Only $1.9 \%$ of the E. coli cells lost the plasmid pCDF-SLA-cpcS. Under induced conditions, $16.2 \%$ of the $E$. coli cells lost the plasmid pCDF-SLA-cpcS, $10.6 \%$ of the induced E. coli cells lost the plasmid pRSF-PHo1-pebS, and $6.9 \%$ of the induced $E$. coli cells lost both plasmids. Only $66.3 \%$ of the induced cells retained both expression plasmids (Fig. 3a). These results showed that induction by IPTG led to plasmid loss and heterogenous cell populations. This observation could be confirmed by the results of PCR assays to detect the expression plasmids (Additional file 1: Figure S2). Among 48 randomly selected colonies from the induced cultures, 7 colonies lost pCDF-SLA-cpcS, 6 colonies lost pRSF-PHo1-pebS, 4 colonies lost, and 31 colonies retained both plasmids. Due to lack of the PEB biosynthesis pathway, the E. coli cells retaining pCDF$S L A-c p c S$ could only produce apo-SLA and contributed to the incomplete chromophorylation of recombinant SLA-PEB.

To improve plasmid stability, the biosynthetic pathway for SLA-PEB was reconstructed by using one expression plasmid. The $S L A$ and $c p c S$ sequences were combined into a polycistron and ligated into the first expression cassette in pRSFDuet-1, while PHo1 and pebS were combined into another polycistron and ligated into the second expression cassette in pRSFDuet-1 (Fig. 1). The resulting plasmid pRSF-SLA-cpcS-PHo1-pebS was transformed into $E$. coli $\mathrm{BL}(\mathrm{DE} 21)$, generating the strain SLAV2. Under uninduced conditions, no $E$. coli cells lost the expression plasmid. Under induced conditions, $5.2 \%$ of the $E$. coli cells lost the expression plasmid (Fig. 3b). This result demonstrated an improved plasmid stability in the strain SLA-V2. It should be noted that the plasmid-bearing cells had an entire SLA-PEB biosynthesis pathway, as indicated by PCR amplification of the whole expression cassettes containing the foreign genes (Additional file 1: Figure S3).

SLA-PEB purified from the strain SLA-V2 had a chromophorylation ratio of $38.6 \%$, which was 2.4 -fold higher than that purified from SLA-V1 (Table 2). The results confirmed the speculation that plasmid stability is an important factor determining the chromophorylation ratio of recombinant PBP. Considering that both Sm and $\mathrm{Km}$ are needed during fermentation of the strain SLA-V1 while only $\mathrm{Km}$ is needed for the cultivation of the strain SLA-V2, the cost for production of SLA-PEB in large scale fermentation will be reduced when the strain SLA-V2 is used. From these results, it can be concluded that when a phycobiliprotein biosynthetic pathway was constructed in recombinant $E$. coli, a single-expression plasmid was preferable to two or multiple expression plasmids.

\section{Molecular evolution of $\mathrm{CpcS}$ for the improvement of chromophorylation efficiency}

The incomplete chromophorylation of SLA-PEB purified from strain SLA-V2 indicated that there were still factor(s) limiting the chromophorylation of recombinant SLA-PEB. Both PEB depletion and low activity and/or expression level of $\mathrm{CpcS}$ would cause incomplete chromophorylation. It was shown by HPLC analysis that PEB accumulated in SLA-V2 cells (Additional file 1: Figure S4A). These data suggested that incomplete chromophorylation of the recombinant PBP was not limited by the availability of PEB. Instead, it was due to low activity and/or expression level of $\mathrm{CpcS}$.

Directed evolution is an efficient strategy for altering the catalytic characteristics of enzymes. Generally, high throughput screening of rare but desirable clones from a mutant library is the most critical step in laboratory directed evolution [29]. To improve the catalytic performance of $\mathrm{CpcS}$, a directed evolution strategy was developed based on agar plate screening (Fig. 4). The wild type clones appeared pink on agar plates, while the clones expressing CpcS mutants with increased activity had 


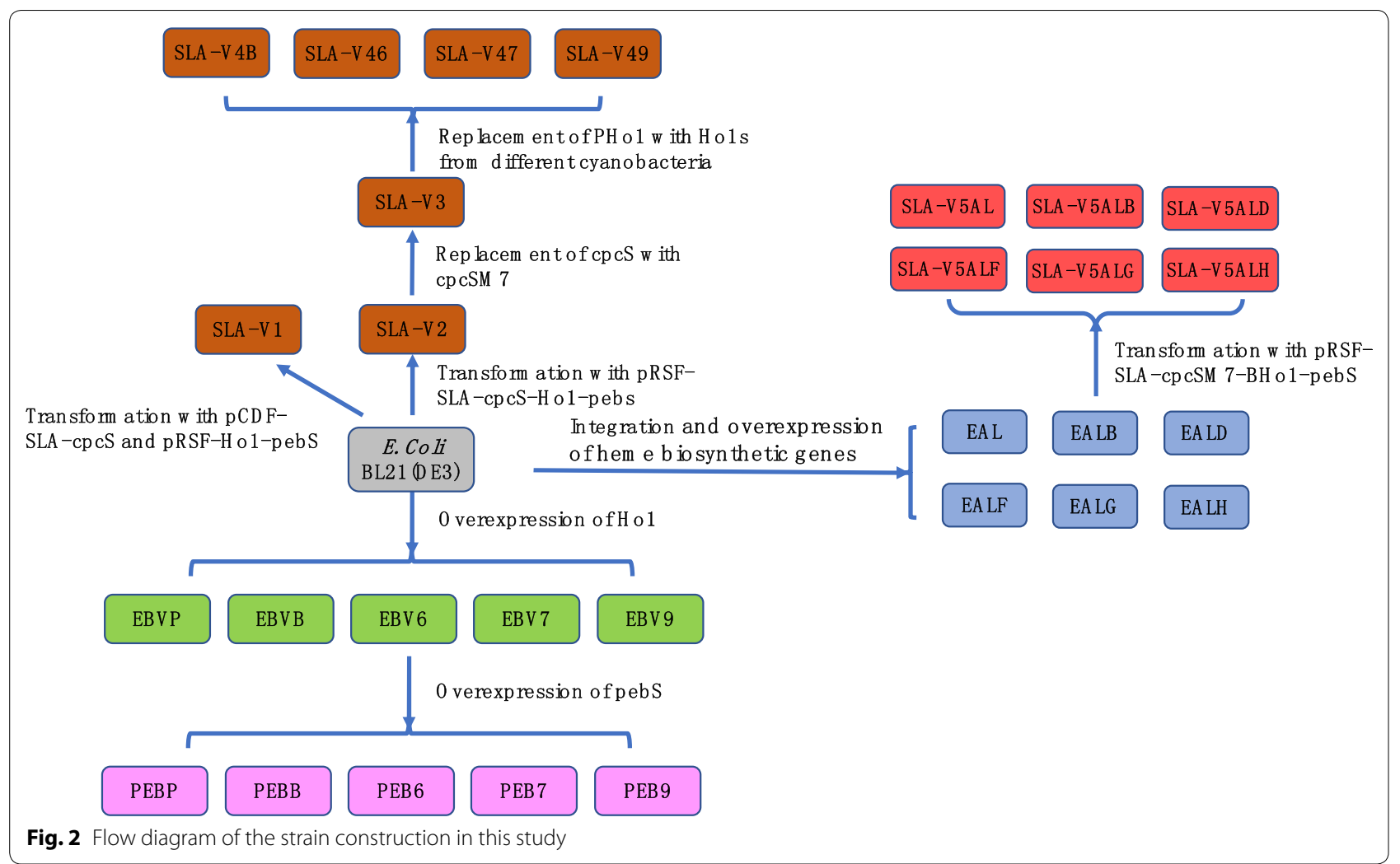

a deep color. A mutant library of approximately $5 \times 10^{4}$ clones was created by random mutagenesis using error-prone PCR. The insertion rate of the library was $92.6 \%$, and the average mutation rate was 5.3 mutations per $1000 \mathrm{bp}$, as estimated by DNA sequencing of 48 randomly selected colonies. Seventeen colonies were selected from the mutant library based on color change. To examine whether these strains indeed had enhanced chromophorylation ability, recombinant SLA-PEB was purified from these strains. Five strains were confirmed to be authentic positive mutants with increased chromophorylation ratios (Table 2). DNA sequencing revealed that the mutants encoded single or multiple amino acid substitutions. The enhanced performance for SLA-PEB chromophorylation might result from enhanced affinity for PEB and higher catalytic efficiency of the CpcS mutant. Among these five colonies, the strain SLA-V3-7 (denoted as SLA-V3) expressing CpcSM7 had the best performance, producing SLA-PEB with a chromophorylation ratio of $64.7 \%$.

\section{Phycobilin biosynthesis using Ho1 from different cyanobacteria}

Although the chromophorylation ratio of SLA-PEB in strain SLA-V3 was elevated significantly, there was still a fraction of SLA-PEB in its apo-form. PEB biosynthesis in the recombinant $E$. coli cells was achieved via expression of $\mathrm{PHo1}$ and pebS. Endogenous heme served as the precursor for PEB biosynthesis. The conversion of heme to biliverdin IX was catalyzed by the heme oxygenase, and then the conversion of biliverdin IX to PEB was catalyzed by the ferredoxin-dependent bilin reductase pebS (R). HPLC analysis showed that in SLA-V3 cells neither PEB nor BV could be detected (Additional file 1: Figure S4B). We speculated that in strain SLA-V3, the chromophorylation of recombinant SLA-PEB is limited by low Ho1 activity and/or heme depletion.

Here, the directed evolution strategy was also employed, with the aim to increase the catalytic activity of PHo1. Unfortunately, no positive mutant was obtained from the screen. Alternatively, we tried to identify Ho1 homologs with high activity and/or expression levels from different cyanobacteria. Genes coding putative Ho1 can be found in the genome of sequenced cyanobacteria. Four Ho1s from cyanobacteria with diverse growth conditions were chosen as candidates. The marine cyanobacterium Synechococcus sp. PCC 7002 and freshwater cyanobacterium Synechococcus elongatus BP-1 can grow at high temperature [30,31], while the marine cyanobacterium Synechococcus sp. PCC 9311 and freshwater cyanobacterium Synechocystis sp. PCC 6803 grow at room temperature. All Hols were codon optimized and 

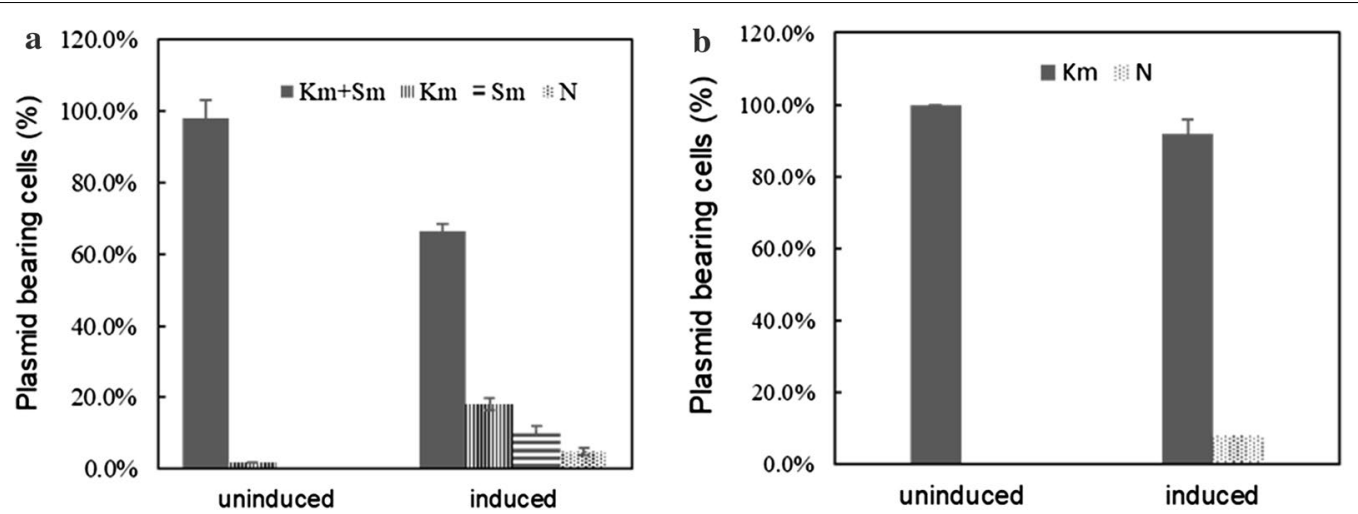

Fig. 3 Plasmid stability for the strains SLA-V1 (a) and SLA-V2 (b). Km + Sm: fraction of E. coli cells bearing pCDF-SLA-cpCS and pRSF-PHo 1-pebS, km: fraction of E. coli cells bearing only pRSF-PHo1-pebS (SLA-V1) or only pRSF-SLA-cpcS-PHo1-pebS (SLA-V2), Sm: fraction of E. coli cells bearing only pCDF-SLA-cpcS, N: fraction of plasmid-free E. coli cells. Data represent mean \pm SD from five independent experiments

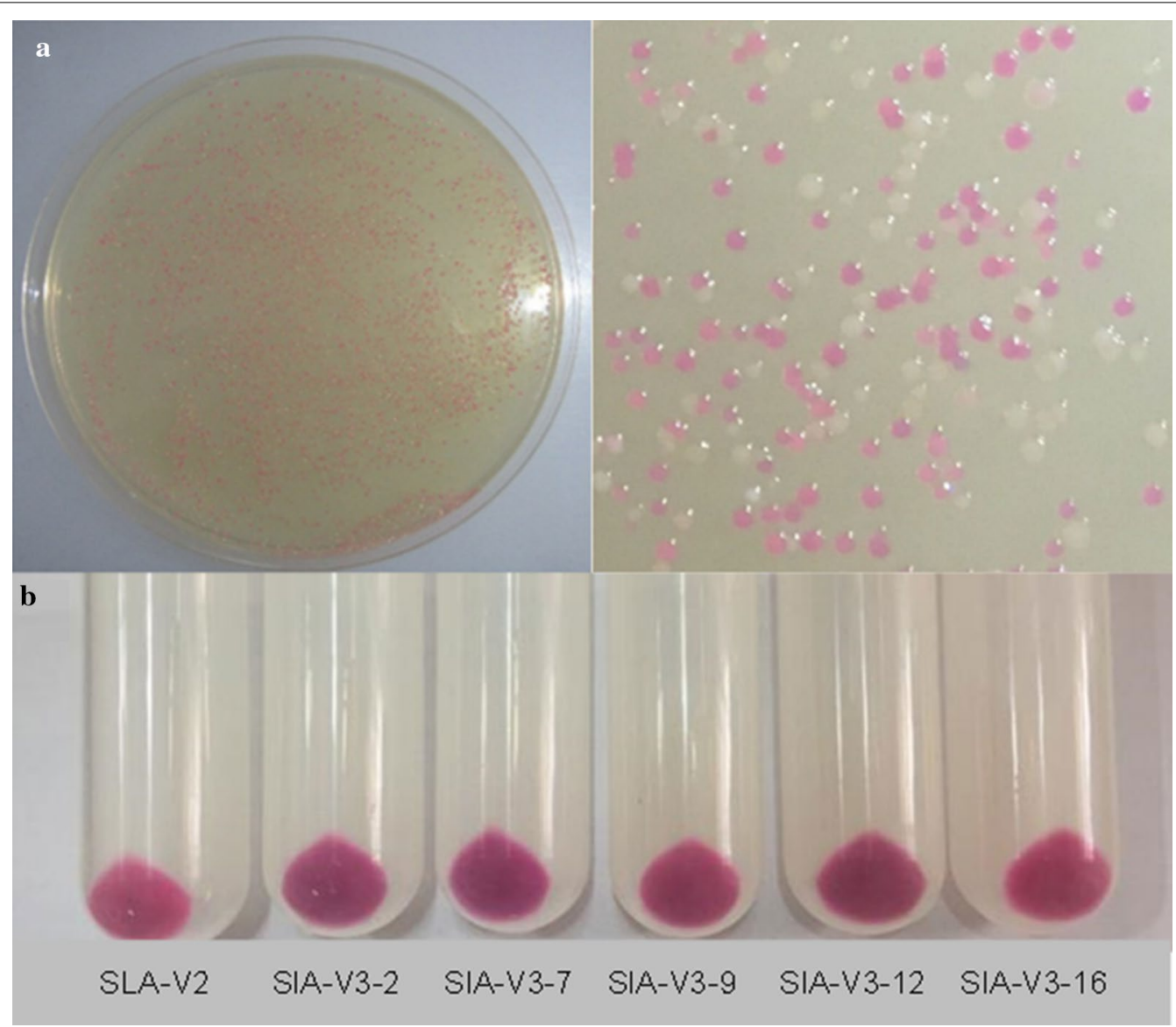

Fig. 4 Directed evolution of CpcS. a The expression of wild-type CpcS resulted in pink clones and a null mutation in CpcS resulted in white clones, while the clones expressing CpcS mutant with enhanced activities showed red or purple coloration, which could be easily distinguished from the library. $\mathbf{b}$ Cell pellets of the wild type and five selected mutants

expressed in E. coli. The catalytic abilities of these Ho1s to convert heme to $\mathrm{BV}$ in $E$. coli were compared. The $E$. coli strain expressing $B H o 1$ turned green after $24 \mathrm{~h}$ of induction with IPTG, while E. coli strains expressing the other Hols did not show obvious color changes (Fig. 5). HPLC analysis showed that among the five BV-producing 
strains, the strain EBVB had the best performance in BV accumulation, producing 14.3-fold higher BV than the strain BVP. Similarly, the PEB-producing strain PEBB accumulated the highest level of $\mathrm{PEB}$, which was 9.3-fold higher than the strain PEBP. It appeared that the high catalytic ability of BHo1 was attributed to its high expression levels in E. coli, since SDS-PAGE showed that BHo1 was expressed at the highest level among the five Ho1s (Additional file 1: Figure S5).

To examine whether improved PEB accumulation would promote the chromophorylation of recombinant proteins in E. coli, PHo1 in strain SLA-V3 was replaced by different Hols (Fig. 1). A positive correlation between PEB accumulation and chromophorylation ratio of SLAPEB was observed (Fig. 5). SLA-PEB purified from the strain SLA-V4B had a chromophorylation ratio of $83.6 \%$, compared to $64.7 \%$ for protein purified from the strain SLA-V3. These results confirmed that in strain SLA-V3,
PHo1 was a limiting factor for efficient chromophorylation of HT-SLA.

\section{Upregulation of the heme biosynthetic pathway genes for further improvement of chromophorylation efficiency} Heme is an essential molecule for cells due to its involvement in many important processes [32]. In engineered microorganisms that express heme proteins, excessive heme consumption disrupts the host metabolism and limits the production of heme proteins [33, 34]. An increased heme level resulted in a significant enhancement of human hemoglobin production [35]. In this study, endogenous heme served as the precursor for PEB biosynthesis. No free PEB could be detected in the strain SLA-V4B (Additional file 1: Figure S4C), suggesting that heme might be a limiting factor for full chromophorylation of SLA. Increased heme availability would presumably improve chromophorylation efficiency of the recombinant protein. However, the addition of heme is
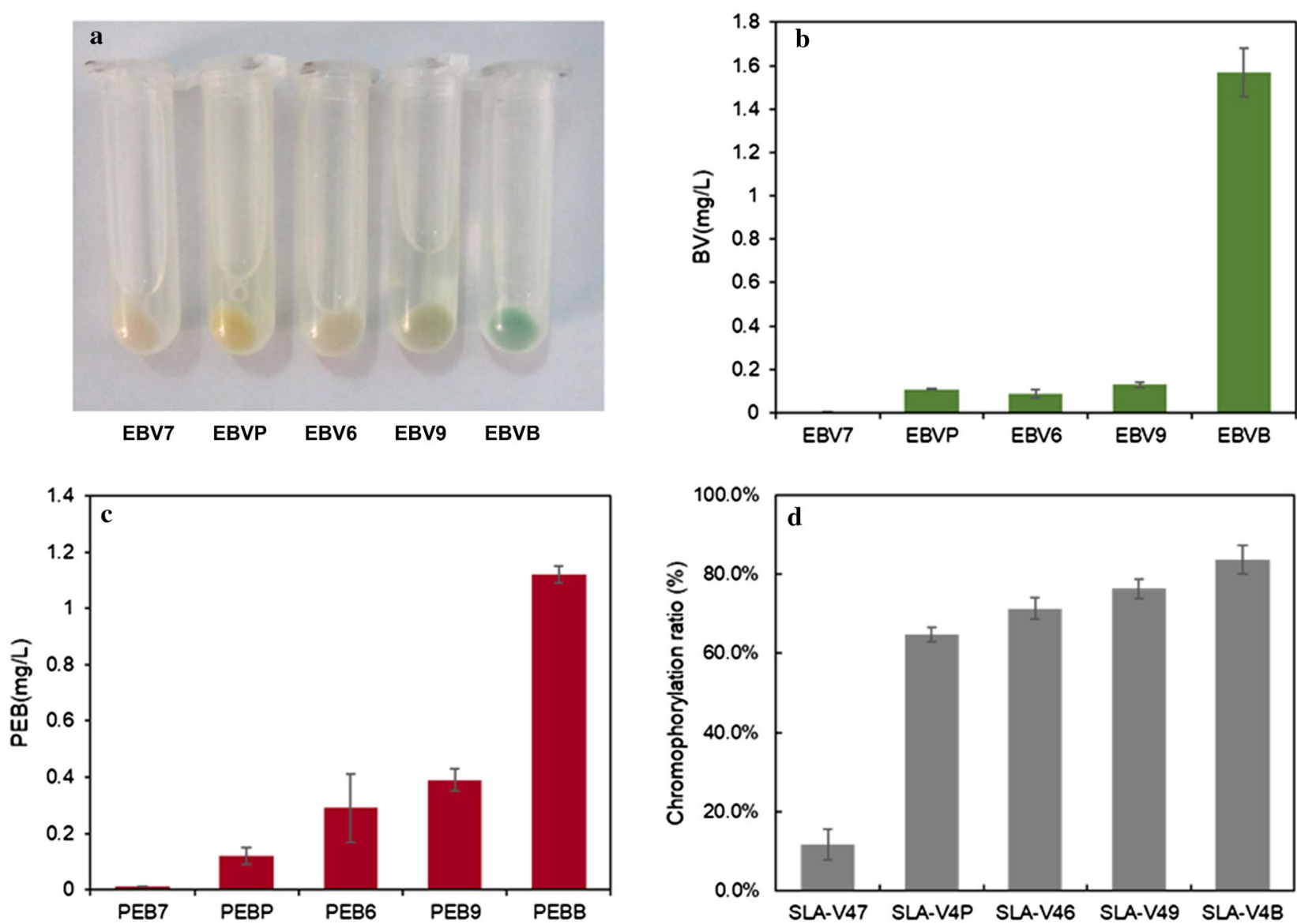

Fig. 5 Effects of different Ho1s on the production of BV and PEB and chromophorylation of SLA-PEB. a Cell pellets for the strains expressing Ho1s from different cyanobacteria. b BV production for the strains expressing Hols from different cyanobacteria. $\mathbf{c}$ PEB production for the strains coexpressing pebS and Ho1s from different cyanobacteria. $\mathbf{d}$ Chromophorylation ratios of SLA-PEB purified from the strains coexpressing pebS and Ho1s from different cyanobacteria. Data represent mean \pm SD from three independent experiments 
not suitable in large-scale production processes due to its high hydrophobicity and cost. Instead, regulation of the heme pathway by metabolic engineering is preferable.

HemL and HemA are the rate-limiting enzymes in the heme biosynthesis pathway in E. coli [36, 37]. In this study, hemL and hemA were combined into an operon and inserted into the chromosomal ArsB locus of E. coli through allelic exchange, generating the strain ELA. Upregulation of hemA and hemL significantly increased heme accumulation (Table 3), demonstrating a critical role of hemA and hemL in heme metabolism. In addition to hemL and hemA, hemB, hemD, hemF, hemG and hem $H$ were reported to be the regulatory targets of heme biosynthesis pathway in E. coli. Overexpression of these genes affected heme biosynthesis pathway [38]. To further improve heme biosynthesis, each of these genes was combined into a polycistron together with hemL and hem $A$ and integrated into the chromosomal ars $B$ locus in E. coli (Table 3). Compared to strain V5AL, strain V5ALD produced more heme, while the strains V5ALB, V5ALF, V5ALG and V5ALH produced equivalent or reduced heme levels. SLA-PEB purified from strain V5ALD showed a chromophorylation ratio of $98.6 \%$. This was the highest chromophorylation ratio reported to date.

\section{SLA-PEB production in fed-batch fermentation}

We noticed that when E. coli strain producing PBPs were cultured on large-scale (e.g., in a fermenter), the chromophorylation ratio of recombinant PBPs was remarkably decreased, though its production level was elevated (data not shown). To examine whether the strain V5ALD had superior performance in PBP production, both $E$. coli strains were cultivated in a $5 \mathrm{~L}$ fermentor. IPTG was added to the culture medium at a final concentration of $1.0 \mathrm{mM}$ when the cell density reached an $\mathrm{OD}_{600}$ of 8.0. Constant feeding mode was employed to achieved high cell density. While both strains had similar cell densities at the end of the fermentation, strain V5ALD produced a higher level of SLA-PEB $(56.4 \mathrm{mg} / \mathrm{L})$ than the strain SLA-V1 (32.5 mg/L). Most importantly, the chromophorylation ratio of the SLA-PEB purified from V5ALD was 96.7\%, which was much higher than that from strain SLA-V1 (Fig. 6).

\section{Conclusion}

An ideal cell factory should demonstrate high efficiency of target product biosynthesis. Inefficient biosynthesis of recombinant PBPs in recombinant $E$. coli leads to the production of a mixture of holo-PBP and

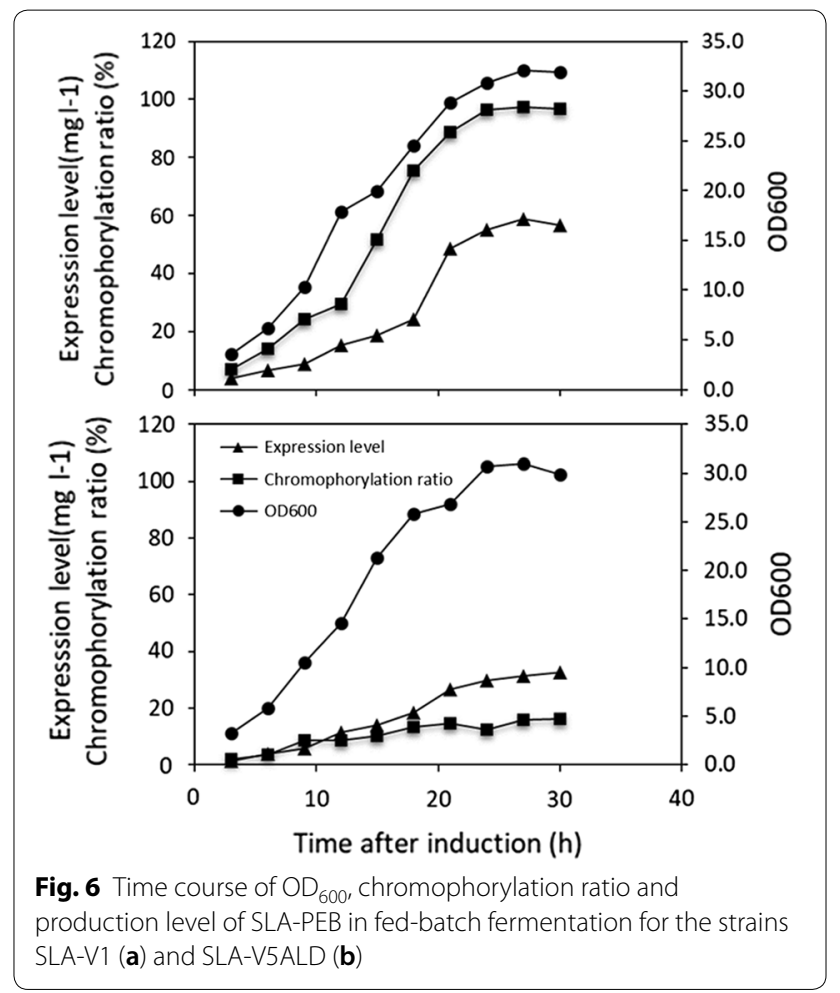

Table 3 Effects of the overexpression of heme biosynthetic genes on heme accumulation and chromophorylation ratio of SLA-PEB

\begin{tabular}{lll}
\hline E. coli strain & Expressed heme gene(s) & Heme ( $\begin{array}{l}\text { Chol/L) } \\
\text { ratio (\%) }\end{array}$ \\
\hline SLA-V4B & - & $1.94 \pm 0.16$ \\
V5AL & hemA, hemL & $2.96 \pm 0.26$ \\
V5ALB & hemA, hemL, hemB & $1.95 \pm 0.17$ \\
V5ALD & hemA, hemL, hemD & $3.30 \pm 0.24$ \\
V5ALF & hemA, hemL, hemF & $2.78 \pm 0.44$ \\
V5ALG & hemA, hemL, hemG & $2.36 \pm 0.18$ \\
V5ALH & hemA, hemL, hemH & $1.70 \pm 0.19$
\end{tabular}


apo-PBP. In this study, the biosynthesis pathway for phycobiliprotein was constructed using one expression plasmid, which had significantly increased plasmid stability. Moreover, strategies for the directed evolution of lyase, the upregulation of heme biosynthetic pathway genes and for overcoming the limiting factors in PEB biosynthesis were employed to enhance the production level and chromophorylation of recombinant phycobiliprotein in E. coli. A chromophorylation ratio of 96.7\% for SLA-PEB was achieved in fed-batch fermentation in this study, and this value was the highest ever reported from an engineered $E$. coli strain. This study demonstrates the validity of a single-expression vector strategy and metabolic engineering for establishing an efficient biosynthetic pathway for PBP production in $E$. coli.

\section{Additional file}

Additional file 1: Table S1. Primers used in this study. Table S2. Recombinant E. coli strains used in this study. Figure S1. Flowchart of directed evolution of CpcS for improving chromophorylation efficiency of SLA-PEB. Figure S2. Colony PCR for detection of the presence of PCDF-SLA-CPCS and pRSF-PHo1-pebS in E. coli strain SLA-V1. The primers are duetup-2 and T7 terminator. The expression cassette of cpcS in pCDF-SLA-cpcS is $813 \mathrm{bp}$, and the expression cassette of Hol and pebS is $1709 \mathrm{bp}$. DNA marker: 8000 bp, 5000 bp, 3000 bp, 2000 bp, 1000 bp, 750 bp, 500 bp, $250 \mathrm{bp}$ and $100 \mathrm{bp}$. Figure S3. Colony PCR for detection of the stability of expression cassette. The primers are duetup- 1 and T7 terminator. The size of expression cassette of SLA, CpcS, PHo1 and pebS is $3433 \mathrm{bp}$. DNA marker: 8000 bp, 5000 bp, 3000 bp, 2000 bp, 1000 bp, 750 bp, 500 bp, $250 \mathrm{bp}$ and $100 \mathrm{bp}$. Figure S4. HPLC analysis of PEB extracted from E. coli strains. A: SLA-V2; B: SLA-V3; C: SLA-V4B. Figure S5. SDS-PAGE analysis of Ho1s expression in E. coli strains. 1: EBV7, 2: EBVP, 3: EBV6, 4: EBV9, 5: EBVB. The calculated molecular weight is $27.1 \mathrm{kDa}$ for $7 \mathrm{Ho1}, 26.9 \mathrm{kDa}$ for $\mathrm{PHo1}$, $27.0 \mathrm{kDa}$ for 6Ho1, $26.7 \mathrm{kDa}$ for $9 \mathrm{Ho} 1$ and $27.1 \mathrm{kDa}$ for $\mathrm{BHo} 1$.

\section{Authors' contributions}

$\mathrm{HC}$ designed and performed the experiments. $\mathrm{HC}$ and PJ wrote the paper. Both authors read and approved the final manuscript.

\section{Author details \\ ${ }^{1}$ Key Laboratory of Experimental Marine Biology, Institute of Oceanology, Chinese Academy of Sciences, Qingdao 266071, China. ${ }^{2}$ Laboratory for Marine Biology and Biotechnology, Qingdao National Laboratory for Marine Science and Technology, Qingdao 266071, China. ${ }^{3}$ Center for Ocean Mega-Science, Chinese Academy of Sciences, Qingdao 266071, China.}

\section{Competing interests}

The authors declare that they have no competing interests.

\section{Availability of data and materials}

All data generated or analyzed during this study are included in this published article and its Additional files.

\section{Consent for publication}

Not applicable.

Ethics approval and consent to participate

Not applicable.

\section{Funding}

This work was supported the development funds of science and technology of Shinan district, Qingdao (2016-3-010-ZH) and National Natural Science Foundation of China (41276164)

\section{Publisher's Note}

Springer Nature remains neutral with regard to jurisdictional claims in published maps and institutional affiliations.

Received: 30 November 2018 Accepted: 28 February 2019

Published online: 20 March 2019

\section{References}

1. Silder W. Phycobilisome and phycobiliprotein structures. In: Bryant DA, editor. The molecular biology of cyanobacteria. Dordrecht: Kluwer; 1994. p. 139-216.

2. Glazer AN. Phycobiliproteins - a family of valuable, widely used fluorophores. J Appl Phycol. 1994;6:105-12.

3. Sonani RR, Rastogi RP, Patel R, Madamwar D. Recent advances in production, purification and applications of phycobiliproteins. World J Biol Chem. 2016;7(1):100-9.

4. Trinquet E, Maurin F, Préaudat M, Mathis G. Allophycocyanin 1 as a nearinfrared fluorescent tracer: isolation, characterization, chemical modification, and use in a homogeneous fluorescence resonance energy transfer system. Anal Biochem. 2001;296(2):232-44.

5. Kim JH, Lee CS, Kim BG. Spore-displayed streptavidin: a live diagnostic toolin biotechnology. Biochem Biophys Res Commun. 2005;331:210-4.

6. Trong IL, Humbert N, Ward TR, Stenkamp RE. Crystallographic analysis of a full-length streptavidin with its C-terminal polypeptide bound in the biotin binding site. J Mol Biol. 2005;356(3):738-45.

7. Dammeyer T, Bagby SC, Sullivan MB, Chisholm SW, Frankenberg-Dinkel N. Efficient phage-mediated pigment biosynthesis in oceanic cyanobacteria. Curr Biol. 2008;18(6):442-8.

8. Scheer H, Zhao KH. Biliprotein maturation: the chromophore attachment. Mol Microbiol. 2008;68:263-76.

9. Saunee NA, Williams SR, Bryant DA, Schluchter WM. Biogenesis of phycobiliproteins: II. CpcS-I and CpcU comprise the heterodimeric bilin lyasethat attaches phycocyanobilin to Cys-82 of beta-phycocyanin and Cys-81 ofallophycocyanin subunits in Synechococcus sp. PCC 7002. J Biol Chem. 2008;283:7513-22.

10. Shen GZ, Schluchter WM, Bryant DA. Biogenesis of phycobiliproteins: i. CpcS-I and CpcU mutants of the cyanobacterium Synechococcus sp. PCC 7002 define a heterodimeric phyococyanobilin lyase specific for beta-phycocyanin and allophycocyanin subunits. J Biol Chem. 2008;283:7503-12.

11. Zhao KH, Su P, Tu JM, Wang X, Liu H, Plöscher M, Eichacker L, Yang B, Zhou M, Scheer H. Phycobilin:cystein-84 biliprotein lyase, a near-universal lyase for cysteine-84-binding sites in cyanobacterial phycobiliproteins. Proc Natl Acad Sci USA. 2007;104(36):14300-5.

12. Shen GZ, Saunée NA, Williams SR, Gallo EF, Schluchter WM, Bryant DA. Identification and characterization of a new class of bilin lyase: the cpcT gene encodes a bilin lyase responsible for attachment of phycocyanobilin to cys-153 on the beta-subunit of phycocyanin in Synechococcus sp. PCC 7002. J Biol Chem. 2006;281(26):17768-78.

13. Tooley AJ, Cai YPA, Glazer AN. Biosynthesis of a fluorescent cyanobacterial C-phycocyanin holo-alpha subunit in a heterologous host. Proc Natl Acad Sci USA. 2001;98:10560-5.

14. Biswas A, Vasquez YM, Dragomani TM, Kronfel ML, Williams SR, Alvey RM, Bryant DA, Schluchter WM. Biosynthesis of cyanobacterial phycobiliproteins in Escherichia coli: chromophorylation efficiency and specificity of all bilin lyases from Synechococcus sp. strain PCC 7002. Appl Environ Microbiol. 2010;76:2729-39.

15. Alvey RM, Biswas A, Schluchter WM, Bryant DA. Attachment of noncognate chromophores to CpcA of Synechocystis sp. PCC 6803 and Synechococcus sp. PCC 7002 by heterologous expression in Escherichia coli. Biochemistry. 2011;50(22):4890-902. 
16. Chen HX, Liu QZ, Zhao J, Jiang P. Biosynthesis, spectral properties and thermostability of cyanobacterial allophycocyanin holo-a subunits. Int Biol Macromol. 2016:88:88-92.

17. Wu J, Chen HX, Zhao J, Jiang P. Fusion proteins of streptavidin and allophycocyanin alpha subunit for immunofluorescence assay. Biochem Eng J. 2017;125:97-103.

18. Ge BS, Sun HX, Feng Y, Yang J, Qin S. Functional biosynthesis of an allophycocyan beta subunit in Escherichia coli. J Biosci Bioeng. 2009;107(3):246-9.

19. Wu J, Chen HX, Jiang P. Chromophore attachment to fusion protein of streptavidin and recombinant allophycocyanin a subunit. Bioengineered. 2018;9(1):108-15.

20. Wang L, Wilson S, Elliott TA. Mutant HemA protein with positive charge close to the $\mathrm{N}$ terminus is stabilized against heme-regulated proteolysis in Salmonella typhimurium. J Bacteriol. 1999;181:6033-41.

21. Sabri S, Steen JA, Bongers M, Nielsen LK, Vickers CE. Knock-in/Knock-out (KIKO) vectors for rapid integration of large DNA sequences, including whole metabolic pathways, onto the Escherichia coli chromosome at well-characterised loci. Microb Cell Fact. 2013;12:60.

22. Datsenko KA, Wanner BL. One-step inactivation of chromosomal genes in Escherichia coli K-12 using PCR products. Proc Natl Acad Sci USA. 2000;97:6640-5.

23. Frankenberg N, Lagarias JC. Phycocyanobilin:ferredoxin oxidoreductase of Anabaena sp. PCC 7120. Biochemical and spectroscopic. J Biol Chem. 2003;278(11):9219-26.

24. Sassa S. Sequential induction of heme pathway enzymes during erythroid differentiation of mouse friend leukemia virus-infected cells. J Exp Med. 1976;143:305-15.

25. Michener JK, Nielsen J, Smolke CD. Identification and treatment of heme depletion attributed to overexpression of a lineage of evolved P450 monooxygenases. Proc Natl Acad Sci USA. 2012;109(47):19504-9.

26. Xu JS, Li WJ, Wu J, Zhang Y, Zhu Z, Liu JJ, Hu ZY. Stability of plasmid and expression of a recombinant gonadotropin-releasing hormone $(\mathrm{GnRH})$ vaccine in Escherichia coli. Appl Microbiol Biotechnol. 2006;73(4):780-8.
27. Mathur A, Chand S. Model-based evaluation of plasmid segregational instability in repeated batch culture with recombinant Escherichia coli. Chem Eng J. 2009;153:227-30.

28. Popov M, Petrov S, Nacheva G, Ivanov I, Reichl U. Effects of a recombinant gene expression on ColE1-like plasmid segregation in Escherichia coli. BMC Biotechnol. 2011;11:18

29. Schmidt-Dannert C, Arnold FH. Directed evolution of industrial enzymes. Trends Biotechnol. 1999;17:135-6.

30. Yamaoka T, Satoh K, Katoh S. Photosynthetic activities of a thermophilic blue-green alga. Plant Cell Physiol. 1978;19:943-54.

31. Ludwig M, Bryant DA. Synechococcus sp. strain PCC 7002 transcriptome: acclimation to temperature, salinity, oxidative stress, and mixotrophic growth conditions. Front Microbiol. 2012;3:354.

32. Ilka UH, Martina J, Dieter J. The biochemistry of heme biosynthesis. Arch Biochem Biophys. 2008;474:238-51.

33. Sudhamsu J, Kabir M, Airola MV, Patel BA, Yeh SR, Rousseau DL, Crane BR. Co-expression of ferrochelatase allows for complete heme incorporation into recombinant proteins produced in E. coli. Protein Expr Purif. 2010;73(1):78-82.

34. Krainer FW, Capone S, Jäger M, Vogl T, Gerstmann M, Glieder A, Herwig C, Spadiut O. Optimizing cofactor availability for the production of recombinant heme peroxidase in Pichia pastoris. Microb Cell Fact. 2015;14:4.

35. Liu L, Martínez JL, Liu Z, Petranovic D, Nielsen J. Balanced globin protein expression and heme biosynthesis improve production of human hemoglobin in Saccharomyces cerevisiae. Metab Eng. 2014;21:9-16.

36. Chen W, Russell CS, Murooka Y, Cosloy SD. 5-Aminolevulinic acid synthesis in Escherichia coli requires expression of hemA. J Bacteriol. 1994;176:2743-6.

37. Verderber E, Lucast LJ, Van Dehy JA, Cozart P, Etter JB, Best EA. Role of the hemA gene product and delta-aminolevulinic acid in regulation of Escherichia coli heme synthesis. J Bacteriol. 1997;179(14):4583-90.

38. Zhang J, Kang Z, Chen J, Du GC. Optimization of the heme biosynthesis pathway for the production of 5-aminolevulinic acid in Escherichia coli. Sci Rep. 2015;26(5):8584.
Ready to submit your research? Choose BMC and benefit from:

- fast, convenient online submission

- thorough peer review by experienced researchers in your field

- rapid publication on acceptance

- support for research data, including large and complex data types

- gold Open Access which fosters wider collaboration and increased citations

- maximum visibility for your research: over $100 \mathrm{M}$ website views per year

At $\mathrm{BMC}$, research is always in progress.

Learn more biomedcentral.com/submissions 